\title{
Decision support systems: Detecting factors influencing on export activities
}

\author{
Nafiseh Asgharnia $^{a^{*}}$ Abdollah Naami ${ }^{\mathrm{b}}$ and Abdolhamid Hajipour Shoshtari ${ }^{\mathrm{b}}$
}

${ }^{a}$ Department of Management, Tehran South Branch, Islamic Azad University, Tehran, Iran

${ }^{b}$ Faculty member, Department of Management, Tehran South Branch, Islamic Azad University, Tehran, Iran

\section{H R O N I C L E}

\section{Article history:}

Received April 20, 2015

Received in revised format May

10, 2015

Accepted July 202015

Available online

July 292015

Keywords:

Tehran Stock Exchange

Decision support system

Export activities

\begin{abstract}
A B S T R A C T
Decision support system (DSS) normally consists of a set of related computer programs and the data required to help with analysis and decision-making within an organization. Many software vendors claim their decision support, analytics or business intelligence applications may provide a competitive advantage by providing different facilities such as business intelligence tools, business performance management software, data mining tools, etc. This paper presents an empirical investigation to determine different DSS factors influencing on development of export activities on selected firms which are active in Tehran Stock Exchange. The study designs a questionnaire consists of 35 questions and distributes it among 211 randomly selected managers who were involved in export activities. Cronbach alpha has been calculated as 0.817 , which is well above the minimum desirable level. Using principle component analysis, the study has detected five factors including internal resources, management approach, quality of data, efficiency of data and organizational approach, which influence the most on export activities.
\end{abstract}

\section{Introduction}

There are literally many studies on learning the effects of various factors on export activities (Leonidou \& Katsikeas, 1996). Stöttinger and Schlegelmilch (1998) performed an empirical investigation on the usefulness of the psychic distance concept on export development in US and compared the results with Japan, Germany, Finland and Austria. Wiedersheim-Paul et al. (1978) developed a model that emphasizes on the relative importance of a business activities and "pre-export" behavior for the export start. The model was based both on more "traditional" research in international business and recent developments in location theory. Bhagwati (1988) evaluated some arguments against the adoption of an export-promoting (EP) trade strategy. The study considered past experiences with trade strategies, and distinguished between the old and new export pessimism. They reported that an EP policy could remain the preferred option provided developing countries forcefully join with the industrial countries in strategies to contain protectionist threats and to preserve and expand an open trading system. One of the most popular techniques for handling different sorts of data for making managerial decision is to use Decision Support Systems for analysing the data. 
Decision support system (DSS) normally consists of a set of related computer programs and the data required to help with analysis and decision-making within an organization. Many software vendors claim their decision support, analytics or business intelligence applications may provide a competitive advantage by providing different facilities such as business intelligence tools, business performance management software, data mining tools, etc. Information technology has created the relationships among firms and their suppliers, channels, and buyers. Information systems, on the other hand, may cross firm boundaries (Sharma et al., 2015). These inter-organizational systems have become common boundaries of several industries. Specific decision support systems may also reduce the power of buyers and/or suppliers. Sophisticated decision support systems may remove some barriers that reduce the threat of entrants. For instance, data and the system for learning it becomes a corporate asset that is hard to build for new entrants. Knowledge in a knowledge-driven DSS may only be achieved through a deep experience in the industry. A specific DSS may assist to differentiate a product or improve service and it can reduce the threat from substitute products. In addition, some DSS may help managers reduce the cost of rivalry actions by targeting expenditures and in some cases DSS may reduce the requirements for competitive actions and reactions.

Carmignani and Avom (2010) measured social development by a combination of health and education outcomes and resource intensity by the share of primary goods in total merchandise exports. They reported that, after controlling for per-capita income and other macroeconomic factors, a higher dependence on primary commodity exports was negative for social development. Silva et al. (2014) developed a Web-based Multi-criteria Spatial DSS for the assessment of environmental sustainability of dairy farms. They used a Web based methodological framework for a fully integrated system of GIS and a specific multiple criteria decision making attribute (MCDA) method - ELECTRE TRI to make appropriate managerial decisions. Ben-Zvi (2012) investigated DSS by evaluating the factors that enhance their perceived effectiveness and their effect on performance using a simulation exercise with 652 senior graduate students who developed DSS and reported on the systems created. They reported that DSS users who perceive the system as effective correlate to improved firm performance. However, investing significant human resources in developing a system would not necessarily guarantee enhanced performance.

Azad et al. (2013) presented an empirical investigation to determine important factors influencing DSSs and detected system, analysis and transaction as important issues. Azad et al. (2014), in other survey, performed an empirical investigation to determine important factors influencing data security in Municipality is city of Tehran, Iran and determined six factors influencing feasibility study, organizational learning, management strategy, enterprise resource management, process approach and the acceptance.

\section{The proposed study}

This paper presents an empirical investigation to determine different DSS factors influencing on development of export activities on selected firms which are active in Tehran Stock Exchange. The study designs a questionnaire consists of 35 questions and distributes it among 211 randomly selected managers who were involved in export activities. Cronbach alpha has been calculated as 0.817, which is well above the minimum desirable level. In addition, Bartlett's Test of Sphericity yields a Chi-Square value of 2596.94 with Sig. $=0.000$. Table 1 demonstrates the summary of some basic statistics associated with the data. As we can observe from the results of Table 1, all data are within desirable levels and we can therefore proceed the next step. Table 2 shows the results of Total variance for all components. Moreover Fig. 1 shows the results of Scree plot. 
Scree Plot

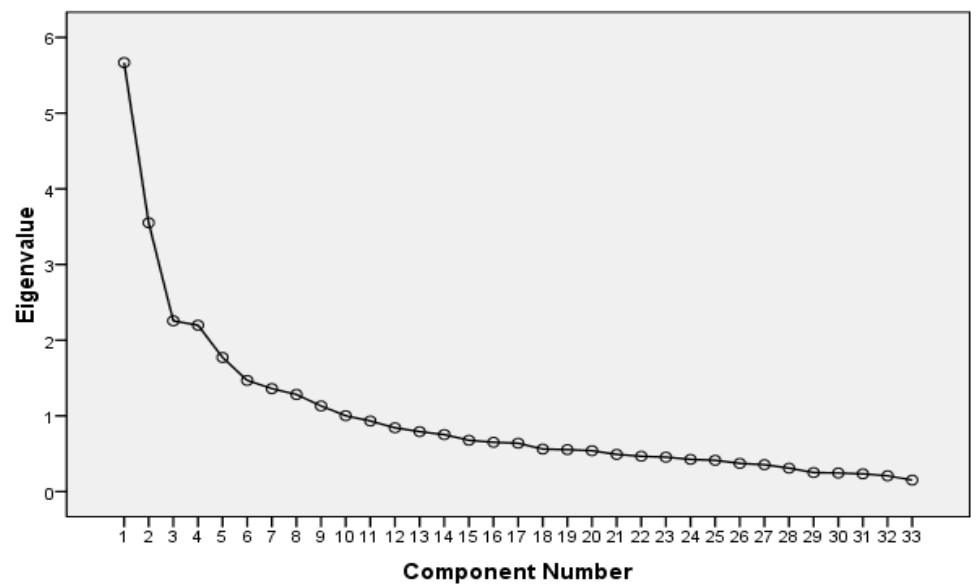

Fig. 1. The results of Scree plot

Table 1

The summary of some basic statistics

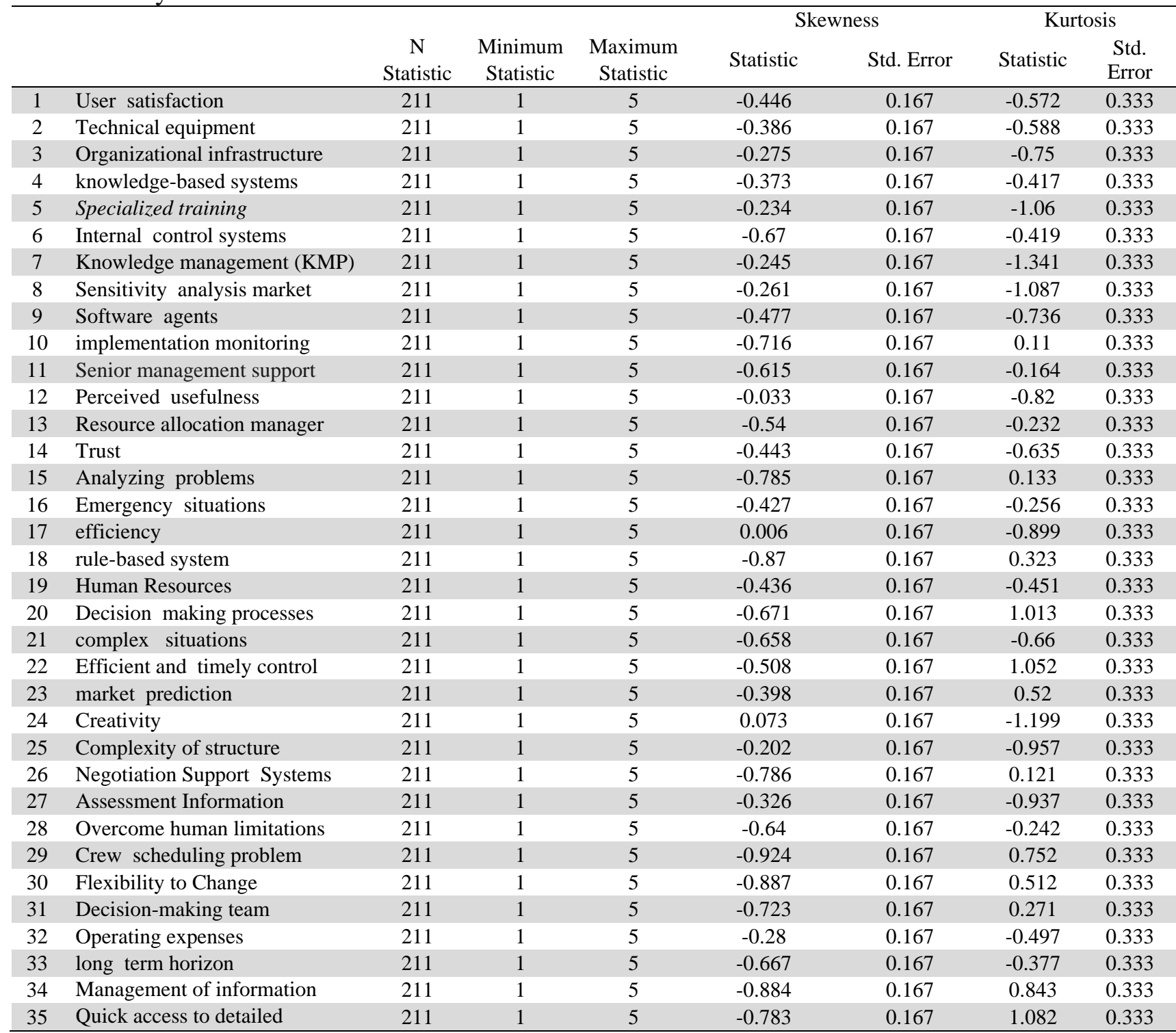


Table 2

The summary of total variance

\begin{tabular}{|c|c|c|c|c|c|c|c|c|c|}
\hline \multirow[b]{2}{*}{ Component } & \multicolumn{3}{|c|}{ Initial Eigen values } & \multicolumn{3}{|c|}{ Extraction Sums of Squared Loadings } & \multicolumn{3}{|c|}{ Rotation Sums of Squared Loadings } \\
\hline & Total & $\%$ of & Cumulative & Total & $\%$ of & Cumulative & Total & $\%$ of & Cumulative \\
\hline 1 & 5.668 & 17.177 & 17.177 & 5.668 & 17.177 & 17.177 & 3.8 & 11.514 & 11.514 \\
\hline 2 & 3.551 & 10.761 & 27.938 & 3.551 & 10.761 & 27.938 & 3.702 & 11.219 & 22.733 \\
\hline 3 & 2.256 & 6.836 & 34.774 & 2.256 & 6.836 & 34.774 & 2.191 & 6.639 & 29.372 \\
\hline 4 & 2.198 & 6.66 & 41.434 & 2.198 & 6.66 & 41.434 & 2.132 & 6.459 & 35.831 \\
\hline 5 & 1.771 & 5.368 & 46.802 & 1.771 & 5.368 & 46.802 & 2.115 & 6.409 & 42.24 \\
\hline 6 & 1.468 & 4.45 & 51.252 & 1.468 & 4.45 & 51.252 & 1.725 & 5.228 & 47.469 \\
\hline 7 & 1.36 & 4.12 & 55.372 & 1.36 & 4.12 & 55.372 & 1.617 & 4.9 & 52.368 \\
\hline 8 & 1.282 & 3.885 & 59.257 & 1.282 & 3.885 & 59.257 & 1.602 & 4.854 & 57.223 \\
\hline 9 & 1.13 & 3.425 & 62.683 & 1.13 & 3.425 & 62.683 & 1.592 & 4.824 & 62.046 \\
\hline 10 & 1.002 & 3.035 & 65.718 & 1.002 & 3.035 & 65.718 & 1.212 & 3.672 & 65.718 \\
\hline 11 & 0.932 & 2.825 & 68.543 & & & & & & \\
\hline 12 & 0.842 & 2.552 & 71.095 & & & & & & \\
\hline 13 & 0.792 & 2.399 & 73.494 & & & & & & \\
\hline 14 & 0.753 & 2.282 & 75.775 & & & & & & \\
\hline 15 & 0.678 & 2.054 & 77.829 & & & & & & \\
\hline 16 & 0.651 & 1.973 & 79.802 & & & & & & \\
\hline 17 & 0.639 & 1.936 & 81.738 & & & & & & \\
\hline 18 & 0.561 & 1.701 & 83.439 & & & & & & \\
\hline 19 & 0.554 & 1.679 & 85.118 & & & & & & \\
\hline 20 & 0.539 & 1.634 & 86.752 & & & & & & \\
\hline 21 & 0.49 & 1.485 & 88.238 & & & & & & \\
\hline 22 & 0.466 & 1.413 & 89.65 & & & & & & \\
\hline 23 & 0.454 & 1.376 & 91.026 & & & & & & \\
\hline 24 & 0.424 & 1.286 & 92.313 & & & & & & \\
\hline 25 & 0.413 & 1.253 & 93.565 & & & & & & \\
\hline 26 & 0.372 & 1.127 & 94.692 & & & & & & \\
\hline 27 & 0.355 & 1.075 & 95.767 & & & & & & \\
\hline 28 & 0.309 & 0.936 & 96.703 & & & & & & \\
\hline 29 & 0.25 & 0.758 & 97.461 & & & & & & \\
\hline 30 & 0.245 & 0.741 & 98.202 & & & & & & \\
\hline 31 & 0.234 & 0.708 & 98.91 & & & & & & \\
\hline 32 & 0.208 & 0.631 & 99.541 & & & & & & \\
\hline 33 & 0.151 & 0.459 & 100 & & & & & & \\
\hline
\end{tabular}

As we can see from the results of Scree plot, there are five DSS items, which influence the most on the development of export activities. Table 3 also shows the results of principle component analysis after rotation.

\section{Discussion and conclusion}

According to the results of principal component analysis with rotation, the study has detected five important factors influencing the most on development of export activities including internal resources, management approach, quality of data, efficiency of data and organizational approach. The first and the most important factor in terms of factor loading is associated with internal resources and it includes five sub-components including Technical equipment, Human Resources, Software agents, Organizational infrastructure and Resource allocation manager with factor loadings of .867, .856, .825, .812 and .495, respectively. The second factor is related to management approaches and it includes six sub components including Flexibility to Change, Decision-making team, Management of information systems, Senior management support, implementation monitoring and Emergency situations with factor loadings of .801, .778, .694, .694, .671 and .574, respectively. The third component is associated with quality of data with four components including Assessment Information, Trust, User satisfaction and Negotiation Support Systems and the factor loadings of .816, .645, .554 and .548, respectively. The fourth factor, efficiency of data, consists of four factors including Quick access to detailed information, Decision making processes, Efficient and timely control and Analyzing problems with factor loadings 
of .722, .709, .701 and .566, respectively. The last factor, organizational approach, also consists of Complexity of structure, Internal control systems, Perceived usefulness, knowledge-based systems and Crew scheduling problem with factors loading of .757, .668, .606, .565 and .380, respectively.

Table 3

The summary of principle component analysis after rotation

\begin{tabular}{|c|c|c|c|c|c|c|c|c|c|c|c|}
\hline & \multirow{2}{*}{ Factor } & \multicolumn{10}{|c|}{ Rotated Component Matrix ${ }^{a}$} \\
\hline & & 1 & 2 & 3 & 4 & 5 & 6 & 7 & 8 & 9 & 10 \\
\hline q2 & Technical equipment & 0.867 & & & & & & & & & \\
\hline q19 & Human Resources & 0.856 & & & & & & & & & \\
\hline q9 & Software agents & 0.825 & & & & & & & & & \\
\hline q3 & Organizational infrastructure & 0.812 & & & & & & & & & \\
\hline q13 & Resource allocation manager & 0.495 & 0.346 & & & & & & & & \\
\hline q30 & Flexibility to Change & & 0.801 & & & & & & & & \\
\hline q31 & Decision-making team & & 0.778 & & & & & & & & \\
\hline q34 & Management of information & & 0.694 & & & & & & & & \\
\hline q11 & Senior management support & & 0.694 & & & & & & & & \\
\hline q10 & implementation monitoring & & 0.671 & & & & & & & & \\
\hline q16 & Emergency situations & & 0.574 & & & & & & & & \\
\hline q27 & Assessment Information & & & 0.816 & & & & & & & \\
\hline q14 & Trust & & & 0.645 & & & & & & & \\
\hline q1 & User satisfaction & & & 0.554 & & & & & & & \\
\hline q26 & Negotiation Support Systems & & 0.352 & 0.548 & & & - & & & & \\
\hline q35 & Quick access to detailed & & & & 0.722 & & & & & & \\
\hline q20 & Decision making processes & & & & 0.709 & & & & & & \\
\hline q22 & Efficient and timely control & & & & 0.701 & & & & & & \\
\hline q15 & Analyzing problems & & & & 0.566 & & & & & & \\
\hline q25 & Complexity of structure & & & & & 0.757 & & & & & \\
\hline q6 & Internal control systems & & & & & 0.668 & & & & & \\
\hline q12 & Perceived usefulness & & & & & 0.606 & & 0.52 & & & \\
\hline q4 & knowledge-based systems & & & & & 0.565 & & & & & \\
\hline q29 & Crew scheduling problem & & & & & 0.38 & & & & & 0.379 \\
\hline q5 & Specialized training & & & & & & 0.743 & & & & \\
\hline q8 & Sensitivity analysis market & 0.36 & & & & & 0.669 & & & & \\
\hline q17 & efficiency & & & & & & & 0.791 & & & \\
\hline q28 & Overcome human limitations & & 0.365 & & & & & 0.365 & -0.36 & & \\
\hline q32 & Operating expenses & & & & & & & & 0.699 & & \\
\hline q18 & rule-based system & 0.345 & & & & & & & 0.541 & & \\
\hline q21 & complex situations & & & & & & & & & 0.835 & \\
\hline q7 & Knowledge management (KMP) & & & & & & & & & 0.675 & \\
\hline q23 & market prediction & & & & & & & & & & 0.774 \\
\hline
\end{tabular}

\section{Acknowledgement}

The authors would like to thank the anonymous referees for constructive comments on earlier version of this paper.

\section{References}

Azad, N., Sadeghi, M., Zarifi, S., \& Farkian, M. (2013). An exploration study to find important factors influencing on decision support systems. Management Science Letters, 3(9), 2517-2520.

Azad, N., Abbasi, N., \& Zarifi, S. (2014). A study to determine influential factors on data security. Decision Science Letters, 3(1), 57-64.

Ben-Zvi, T. (2012). Measuring the perceived effectiveness of decision support systems and their impact on performance. Decision Support Systems, 54(1), 248-256.

Bhagwati, J. N. (1988). Export-promoting trade strategy: issues and evidence. The World Bank Research Observer, 3(1), 27-57. 
Carmignani, F., \& Avom, D. (2010). The social development effects of primary commodity export dependence. Ecological Economics, 70(2), 317-330.

Leonidou, L. C., \& Katsikeas, C. S. (1996). The export development process: an integrative review of empirical models. Journal of international business studies, 517-551.

Sharma, R. N., Chand, N., Sharma, V., \& Yadav, D. (2015). Decision support system for operation, scheduling and optimization of hydro power plant in Jammu and Kashmir region. Renewable and Sustainable Energy Reviews, 43, 1099-1113.

Silva, S., Alçada-Almeida, L., \& Dias, L. C. (2014). Development of a Web-based Multi-criteria Spatial Decision Support System for the assessment of environmental sustainability of dairy farms. Computers and Electronics in Agriculture, 108, 46-57.

Stöttinger, B., \& Schlegelmilch, B. B. (1998). Explaining export development through psychic distance: enlightening or elusive?. International Marketing Review, 15(5), 357-372.

Wiedersheim-Paul, F., Olson, H. C., \& Welch, L. S. (1978). Pre-export activity: The first step in internationalization. Journal of International Business Studies, 9(1), 47-58. 